\title{
Childhood vitiligo: Clinical epidemiological profile
}

\author{
Asmae Lahlou, Hanane Baybay, Salim Gallouj, Fatima-Zohra Mernissi
}

Department of Dermatology, University Hospital Hasssan II, Fez, Morocco

Corresponding author: Dr. Asmae Lahlou, E-mail: lahlouasmae@gmail.com

\begin{abstract}
Objective: To study the clinical and the epidemiologic profiles of childhood vitiligo. Patients and Methods: We prospectively analyzed the clinical data of children with vitiligo presented to the dermatology derpartement at University Hospital - Fès for 5 years from May 2011 to May 2016. This study included 31 patients. All patients were assessed for the natural history, clinical characteristics, family history, and associated abnormalities of vitiligo. Results: Of the 31 children with vitiligo $9(29,03 \%)$ were boys and $21(67.74 \%)$ were girls. The mean age of onset of the vitiligo was 10 years. The mean duration of the disease was 38,9 weeks. The most common type of vitiligo was vitiligo vulgaris (49.5\%) followed by focal vitiligo (39\%), acrofacial vitiligo (32\%), and segmental vitiligo (16\%) The most frequent site of onset was the extremities followed by the head and the neck, then the trunk and the genitalia. Of the 31 children with vitiligo, 39\% had a family history and $4 \%$ had an antecedent of autoimmune diesease like le diabète, une thyroïdite, l'anémie et le psoriasis, retrouvé. Conclusion: Our children have a strong family history of vitiligo and they are developing the disease at a slightly older age compared with those of other studies; however, other epidemiologic features appear to be similar to those reported in the previously published studies.
\end{abstract}

Keys words: Vitiligo; Childhood; Depigmentation

\section{INTRODUCTION}

Vitiligo is an acquired, sometimes familial depigmentary disorder of the skin and hair which results from selective destruction of melanocytes. The prevalence of vitiligo ranges from $0.1 \%$ to $2 \%$ in various populations, The exact prevalence in the pediatric population is unknown, vitiligo begins before the age of ten years in about $25 \%$ of cases [1]. The average age in different studies ranges from four to eight years with a very early start possible from the age of three months [2-3]. Vitiligo in childhood can be associated with significant psychological trauma that may have long-lasting effects on the self-esteem of these children.

The existence of congenital forms is controversial [4]. In individuals with fair skin, vitiligo is usually visible after a first sun exposure that will accentuate the contrast with healthy skin. a predominance of girls is noted in all pediatric series [3,5-7]. If all races can be affected, it would seem that the prevalence of child vitiligo is higher in India, but it could be secondary to increased social attention [8]. the objective of this work is to study the clinical and the epidemiologic profiles of childhood vitiligo through the analysis of a series of 31 cases of children with vitiligo.

\section{MATERIALS AND METHODS}

A retrospective analysis was made on records of the patients attending the dermatology derpartement at University Hospital- Fes during 5 years from May 2011 to May 2016. All patients $\leq 17$ years of age with vitiligo referred to the clinic were included in this study. Demographic details of all patients including the age of onset, initial site of onset, duration of disease, associated mucosal involvement, associated diseases, and family history were obtained from the clinic notes.

\section{RESULTS}

Of the total 31 children with vitiligo in the present study 9 (29,03\%) were boys and 21 (67.74\%) were 
girls. The age of onset of vitiligo ranged from 3 mounth to 17 years (mean 10 years). The mean duration of disease was 38,9 weeks. Vitiligo affecting first and second-degree relatives was reported by $12(39 \%)$ patients including 8 girls $(66,6 \%)$ and 4 boys $(33,3 \%)$. The triggering factor was found in $20 \%$ of cases following a psycho-trauma, the affected area was variable up to $40 \%$ in extended forms. The most common clinical type of vitiligo seen in our patients is vitiligo vulgaris (94.5\%), followed by focal vitiligo (39\%), acrofacial vitiligo (32\%), and segmental vitiligo (32\%), in that order (Fig. 1). The most common site of onset was the extremities (45\%), the trunk (35\%), followed by the head and the neck area (32\%), and the genitalia (2\%) (Fig. 2). five children had associated abnormalities. 4 patients atopic eczema, one had positive anti-thyroid antibodies but no showed a clinical evidence of thyroid diseaseLaboratory tests had not shown diabetes, or autoimmune anemia in other patients, the proposed treatment was topical corticosteroids in $13 \%$ of cases, protopic in $61.2 \%$ of cases and in 22 UVB HTL01, $5 \%$ of cases, with good evolution in $42 \%$ and unsatisfactory progress in $58 \%$ of cases.

\section{DISCUSSION}

Many studies state that most vitiligo is primarily acquired early in life, We have attempted to compare our findings with those in the previous studies from different countries, a comparison of the patterns of vitiligo and its associated disorders in different studies, including ours, is represented in Table 1.

The mean age of onset in the pediatric age group has been found to be 4.6 years in an American study [6], 5.6 years in a Korean study [2] 6.2 years in Kuwaiti study [9].

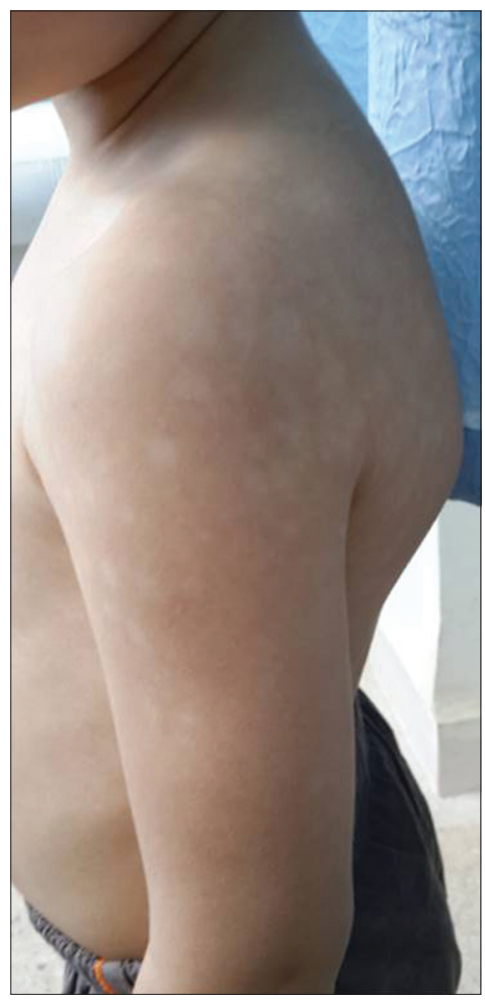

Figure 1: Vitiligo on the back in a child of 5 years old.

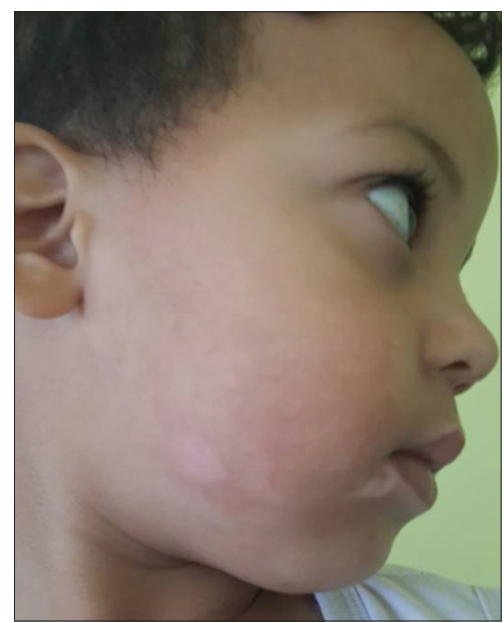

Figure 2: Vitiligo perished orificiel back in a child of 3 years old.

Table 1: Comparison of patterns of vitiligo and observed associated disorders between different studies, including our study

\begin{tabular}{lccccl}
\hline Country of study & $\begin{array}{c}\text { Period of } \\
\text { study (years) }\end{array}$ & $\begin{array}{c}\text { Female } \\
\text { patients (\%) }\end{array}$ & $\begin{array}{c}\text { Mean age of onset } \\
\text { (years) }\end{array}$ & $\begin{array}{c}\text { Positive family } \\
\text { history of vitiligo (\%) }\end{array}$ & $\begin{array}{l}\text { Associated disorders/ } \\
\text { abnormalities }\end{array}$ \\
\hline USA & Not stated & 57,5 & 4,6 & 35 & $\begin{array}{l}\text { Serum autoantiodies } \\
\text { Ocular involvement } \\
\text { Alopecia areta } \\
\text { Antithyroid antibodies } \\
\text { Saudi Arabia }\end{array}$ \\
1 & 63,2 & 7,9 & 36,9 & Atopic dermatitis \\
Kuwait & 1 & 56,3 & 6,2 & & Alopecia areta \\
Korea & 10 & 57,7 & Not stated & 12,2 & $\begin{array}{l}\text { Intestinal parasitosis } \\
\text { Septic foci in teeth }\end{array}$ \\
$\begin{array}{l}\text { North india } \\
1\end{array}$ & 61,1 & Not stated & 3,3 & $\begin{array}{l}\text { Alopecia areta } \\
\text { Antithyroid antibodies } \\
\text { Atopic dermatitis }\end{array}$ \\
\hline
\end{tabular}


Our results reveal that the mean age of onset was 7.9 years, which mean that our patients develop vitiligo in a slightly older age than in others. The exact reasons for this are unclear. Our review show a preponderance of girls in children with vitiligo, similar to the observation made in majority of previously reported studies $[6-9,10]$. Although, two studies from Korea and China noted an almost equal incidence in boys and girls $[2,11,12]$.

The observed female predominance can be explained by their emotional fragility and the most major cosmetic concern of parents that is the case in our context.

Approximately $39 \%$ of patients in our study had a family history of vitiligo We believe that genetic factors play a role herein, as there is a high incidence of consanguineous marriage in our country.

Similar to our finding Halder et al. focal vitiligo was the second most common presentation. However, Jaisankar et al., in their study with 90 children, they reported segmental vitiligo as the second most frequent presentation, occurring in $21 \%$ of patients, closely followed by focal vitiligo in $20.1 \%$. The percentage of segmental vitiligo has been reported to vary from $19 \%$ to $21 \%$ in children $[9,10]$.

The extremities were the most common sites of onset in children in our series (45\%), that differe from other studies or that different from other studies or location of head and neck is the most common $[2,5,9,10]$. The association of vitiligo with other diseases/abnormalities has also been a subject of great interest.

In earlier published reports on childhood vitiligo, vitiligo vulgaris was the most frequent type reported $[9,10]$. In our study as well, this is the most common clinical type seen in $94,5 \%$.

A previous study reported that four children of $33(12.1 \%)$ screened had antithyroid antibodies, although they were all clinically asymptomatic [9]. This is consistent with our finding of antithyroid antibodies in $2,33 \%$ all of them were clinically asymptomatic.

In our study 1 of 31 children $(3,22 \%)$ had associated autoimmune disease namely, alopecia areata. This is consistent with Halder et al. study as they reported two cases of alopecia areata in 82 children $(2.4 \%)$ with vitiligo. One study from Kuwait found $1.1 \%$ of children with vitiligo had alopecia areata [9].

In a study from North India, $1.3 \%$ of children (8 of 625 children) had an associated autoimmune disease including alopecia areata, diabetes mellitus, thyroid disease, Addison's disease, polyglandular syndrome or pemphigus vulgaris [5].

In addition, two studies have reported an increased prevalence of various autoantibodies in patients with vitiligo $[12,13]$. A recent article has reported the presence of thyromegaly, antithyroid antibodies and thyroid dysfunction in significant numbers of children and adolescents with vitiligo $[14,15]$.

\section{CONCLUSION}

We observe that children in our study have a strong family history of vitiligo than other population and are developing the disease at a slightly older age compared with other studies; however, other epidemiologic features appear to be similar to those reported in the previously published studies.

\section{REFERENCES}

1. Howitz J, Brodthagen H, Schwartz M, Thomsen K. Prevalence of vitiligo. Epidemiological survey of the Isle of Bornholm, Denmark. Arch Dermatol. 1997;113:47-52.

2. Cho S, Kang HC, Hahm JH. Characteristics of vitiligo in Korean children. Pediatr Dermatol. 2000;17:189-93.

3. Pr'ci'c S, Duran V, Poljacki M. Vitiligo in childhood. Med Pregl. 2002;55:475-80.

4. Nordlund JJ, Lerner AB. Vitiligo. It is important. Arch Dermatol. 1982;118:5-8.

5. Handa S, Dogra S. Epidemiology of childhood vitiligo: a study of 625 patients from North India. Pediatr Dermatol. 2003;20:207-10.

6. Halder RM, Grimes PE, Cowan CA, Enterline JA, Chakrabarti SG, Kenney Jr JA. Childhood vitiligo. J Am Acad Dermatol. 1987;16:94854.

7. Mazereeuw-Hautier J, Bezio S, Mahe E, Bodemer C, Eschard C, Viseux V, et al. Groupe de recherche clinique en dermatologie pédiatrique (GRCDP). Segmental and nonsegmental childhood vitiligo has distinct clinical characteristics: a prospective observational study. J Am Acad Dermatol. 2010;62:945-9.

8. Handa S, Kaur I. Vitiligo: clinical findings in 1436 patients. J Dermatol. 1999;26:653-7.

9. Halder RM, Grimes PE, Cowan CA, Enterline JA, Chakrabarti SG, Kenney Jr. JA. Childhood vitiligo. J Am Acad Dermatol. 1987;16:94854.

10. Al-Mutairi N, Sharma AK, Al-Sheltawy M, Nour-Eldin O. Childhood vitiligo: a prospective hospital-based study. Australas J Dermatol.2005;46:150-3.

11. Hu Z, Liu JB, Ma SS, Yang S, Zhang XJ. Profile of childhood vitiligo in China: an analysis of 541 patients. Pediatr Dermatol. 2006;23:114-6. 


\section{www.odermatol.com}

12. Jaisankar TJ, Baruah MC, Garg BR. Vitiligo in children. Int J Dermatol. 1992;31:621-3.

13. Betterle C, Caretto A, De Zio A, Pedini B, Veller-Fornasa C, Cecchetto A, Accordi F, Peserico A. Incidence and significance of organ-specific autoimmune disorders (clinical, latent, or only autoantibodies) in patients with vitiligo. Dermatologica. 1985;171:419-23.

14. Naughton GK, Reggiado D, Bystryn JC, Correlation between vitiligo antibodies and extent of depigmentation in vitiligo. J Am Acad Dermatol. 1986;15:978-81.
15. Kurtev A, Dourmishev AL. Thyroid function and autoimmunity in children and adolescents with vitiligo. J Eur Acad Dermatol Venerol. 2004;18:99-117.

Copyright by Asmae Lahlou, et al. This is an open-access article distributed under the terms of the Creative Commons Attribution License, which permits unrestricted use, distribution, and reproduction in any

medium, provided the original author and source are credited.

Source of Support: Nil, Conflict of Interest: None declared. 